\title{
The evidentiary basis of vertebral augmentation: a 2019 update
}

\author{
Reade De Leacy (D) , ${ }^{1}$ Ronil V Chandra, ${ }^{2,3}$ John D Barr, ${ }^{4}$ Allan Brook, ${ }^{5}$ \\ Alessandro Cianfoni, ${ }^{6}$ Bassem Georgy, ${ }^{7}$ Ashu Jhamb, ${ }^{8}$ Paul N M Lohle, ${ }^{9}$ Luigi Manfre, ${ }^{10}$ \\ Stefano Marcia, ${ }^{11}$ Alexander Venmans, ${ }^{9}$ Devin Bageac, ${ }^{12}$ Joshua A Hirsch ${ }^{13}$
}

For numbered affiliations see end of article.

\section{Correspondence to} Dr Reade De Leacy, Neurosurgery, Icahn School of Medicine at Mount Sinai, New York City, NY 10029, USA; reade.deleacy@mountsinai.org

Received 28 September 2019 Revised 20 November 2019 Accepted 21 November 2019 Published Online First 22 January 2020

\section{Linked}

- http://dx.doi.org/10.1136/ neurintsurg-2019-015507

Check for updates

(c) Author(s) (or their employer(s)) 2020. No commercial re-use. See rights and permissions. Published by BMJ.

To cite: De Leacy $R$, Chandra RV, Barr JD, et al. $J$ Neurolntervent Surg 2020;12:442-447.

\section{ABSTRACT}

No aspect of neurointerventional practice has been associated with as longstanding contention and debate as to its effectiveness as has vertebroplasty (VP). Four blinded randomized controlled trials published since 2009 have demonstrated conflicting results regarding a conferred benefit in pain reduction and functional improvement for patients who undergo VP for osteoporotic vertebral compression fractures. Significant heterogeneity exists between each of these trials, which has resulted in difficulty for interventionalists and surgeons to translate the trial findings into routine clinical practice. In addition, patients and their families are ever more enlightened and enabled via the internet and social media to review both medical literature and websites. Without the proper background and context, their decisions may be lacking appropriate and necessary scientific discussion. This review article summarizes the randomized controlled trial data to date, with particular focus on the aforementioned four blinded studies. We will also evaluate the profound impact of the decrease in vertebral augmentation utilization on short- and longterm patient morbidity and mortality using available national and administrative datasets from both within the USA and internationally. We also consider future trial design to help evaluate this procedure and determine its role in modern neurointerventional practice.

\section{INTRODUCTION}

Vertebral compression fractures (VCFs) affect more than 700000 individuals in the USA every year and are most often secondary to osteoporosis or low bone mass. ${ }^{12}$ The medical cost of this type of fracture has been estimated at $\$ 1.2$ billion dollars (US) annually and this figure is projected to grow. Most studies evaluating treatment strategies for VCFs have focused on pain as the predominant symptom and post-treatment outcome measure. However, both asymptomatic and symptomatic fractures have long-term serious consequences in terms of compromising an individual's activities of daily living, independence, and leading to higher rates of mortality. These fractures, and the secondary anatomical deformity that ensues, have profound biomechanical, physiologic and psychological consequences including venous thrombosis and pulmonary embolism secondary to prolonged immobility, as well as further loss of bone and muscle mass, social isolation, and depression. ${ }^{34}$
Percutaneous vertebroplasty (VP) was first described in the treatment of an aggressive cervical vertebral hemangioma over 30 years ago in 1987 by Galibert et al. ${ }^{5}$ In 1989 , a landmark paper was published by Lapras et al in which the authors described their experiences with VP in the treatment of osteoporotic fractures and osteolysis related to vertebral hemangiomas. ${ }^{6}$ The decade following these two publications witnessed further expansion of their technique and the introduction of additional devices including balloon kyphoplasty (BKP), which was developed as a tool intended for fracture reduction and vertebral height restoration.? More recently, innovation has resulted in the availability of vertebral body implant-based technology (instrumented kyphoplasty), biologic cements, and radiofrequency ablative technologies, permitting the treatment of a wider array of patients with more complex presentations including osteoporotic, traumatic, and neoplastic lesions. ${ }^{8-10}$

At the time of writing, more than 4000 articles have been published on VP alone. Despite this, debate and some controversy exist as to the effectiveness of VP with respect to pain and functional status when compared with non-surgical management (NSM), specifically in the osteoporotic population. Indeed, interventional societies have created and published evidence-based guidelines that are supportive of VP and vertebral augmentation (VA) in order to help their members adhere to best practices in the provision of these procedures. ${ }^{11-13}$ This paper will review the current evidence in terms of available randomized controlled trial (RCT) data and summarize the published population and national administrative datasets with respect to short- and long-term morbidity and mortality risk in the VCF patient population.

\section{RANDOMIZED CONTROLLED TRIAL DATA}

As of September 2019, 14 RCTs have been published examining the role of VA in treating osteoporotic compression fractures. ${ }^{14-27}$ A separate prospective RCT is available as a published abstract only. ${ }^{28}$

Trial methodology/design differs significantly between each, if not all, of the published RCTs in terms of patient selection, specifics of the intervention applied to the experimental and control arms, the primary and secondary endpoints, the presence or absence of blinding in outcome evaluation, and the incorporation of clinical follow-up. As a consequence, conflicting results have arisen from this 
Table 1 Summary of randomized controlled studies performed to date investigating the role of vertebroplasty and kyphoplasty in the treatment of acute, subacute, and chronic osteoporotic vertebral compression fractures (OVCF)

\begin{tabular}{|c|c|c|c|c|c|c|c|c|c|c|}
\hline $\begin{array}{l}\text { Study name/ } \\
\text { lead author }\end{array}$ & $\begin{array}{l}\text { Year } \\
\text { published }\end{array}$ & $\begin{array}{l}\text { No of } \\
\text { patients } \\
\text { screened }\end{array}$ & $\begin{array}{l}\text { No of } \\
\text { eligible } \\
\text { patients }\end{array}$ & $\begin{array}{l}\text { No of patients } \\
\text { enrolled }\end{array}$ & $\begin{array}{l}\text { Interventions } \\
\text { performed }\end{array}$ & Blinded & $\begin{array}{l}\text { Fracture } \\
\text { age }\end{array}$ & $\begin{array}{l}\text { Primary } \\
\text { outcome } \\
\text { reached }\end{array}$ & $\begin{array}{l}\text { Secondary } \\
\text { outcome } \\
\text { reached }\end{array}$ & $\begin{array}{l}\text { Clinical } \\
\text { follow-up } \\
\text { performed }\end{array}$ \\
\hline $\begin{array}{l}\text { VERTOS } \\
\text { Voormolen et } \\
\text { al }\end{array}$ & 2007 & NR & NR & 34 & $\begin{array}{l}\text { Vertebroplasty vs } \\
\text { NSM }\end{array}$ & No & $\begin{array}{l}1.5-6 \\
\text { months }\end{array}$ & No & Yes & Yes \\
\hline $\begin{array}{l}\text { FREE } \\
\text { Wardlaw et } a l^{15}\end{array}$ & 2009 & 1269 & 614 & $300(49 \%)$ & $\begin{array}{l}\text { Kyphoplasty vs } \\
\text { NSM }\end{array}$ & No & $<3$ months & Yes & Yes & Yes \\
\hline $\begin{array}{l}\text { INVEST } \\
\text { Kallmes et al }\end{array}$ & 2009 & 1813 & 431 & $131(30 \%)$ & $\begin{array}{l}\text { Vertebroplasty vs } \\
\text { sham procedure }\end{array}$ & Yes & $<12$ months & No & No & No \\
\hline $\begin{array}{l}\text { Buchbinder } \\
\text { et } a l^{17}\end{array}$ & 2009 & 468 & 219 & $78(36 \%)$ & $\begin{array}{l}\text { Vertebroplasty vs } \\
\text { sham procedure }\end{array}$ & Yes & $<12$ months & No & No & No \\
\hline Rousing et $a l^{18}$ & 2010 & NR & NR & 49 & $\begin{array}{l}\text { Vertebroplasty vs } \\
\text { NSM }\end{array}$ & No & $<8$ weeks & No & Yes & Yes \\
\hline $\begin{array}{l}\text { VERTOS II } \\
\text { Klazen et al }{ }^{19}\end{array}$ & 2010 & 934 & 421 & $202(47 \%)$ & $\begin{array}{l}\text { Vertebroplasty vs } \\
\text { NSM }\end{array}$ & No & $<6$ weeks & Yes & Yes & Yes \\
\hline Farrokhi et al ${ }^{20}$ & 2011 & 105 & 82 & $82(100 \%)$ & $\begin{array}{l}\text { Vertebroplasty vs } \\
\text { NSM }\end{array}$ & No & 4-52 weeks & Yes & Yes & Yes \\
\hline Blasco et $a l^{21}$ & 2012 & 219 & 125 & $125(100 \%)$ & $\begin{array}{l}\text { Vertebroplasty vs } \\
\text { NSM }\end{array}$ & No & $<12$ months & No & No & Yes \\
\hline Chen et $a l^{22}$ & 2014 & NR & NR & 96 & $\begin{array}{l}\text { Vertebroplasty vs } \\
\text { NSM }\end{array}$ & No & $>3$ months & Yes & Yes & Yes \\
\hline Leali et $a l^{23}$ & 2016 & NR & NR & 385 & $\begin{array}{l}\text { Vertebroplasty vs } \\
\text { NSM }\end{array}$ & No & $<6$ weeks & No & Yes & Yes \\
\hline Yang et $a l^{24}$ & 2016 & NR & 158 & $135(85 \%)$ & $\begin{array}{l}\text { Vertebroplasty vs } \\
\text { NSM }\end{array}$ & No & $<3$ weeks & Yes & Yes & Yes \\
\hline Wang et $a l^{25}$ & 2016 & 384 & 313 & 217 (69\%) & $\begin{array}{l}\text { Vertebroplasty } \\
\text { vs image-guided } \\
\text { facet joint } \\
\text { injection }\end{array}$ & No & $<8$ weeks & No & Yes & Yes \\
\hline $\begin{array}{l}\text { VOPE* } \\
\text { Hansen et } a l^{28}\end{array}$ & 2016 & NR & NR & 46 & $\begin{array}{l}\text { Vertebroplasty vs } \\
\text { sham procedure }\end{array}$ & No & NR & Yes & Yes & Yes \\
\hline $\begin{array}{l}\text { VAPOUR } \\
\text { Clark et } a l^{26}\end{array}$ & 2016 & 302 & 154 & $120(78 \%)$ & $\begin{array}{l}\text { Vertebroplasty vs } \\
\text { sham procedure }\end{array}$ & Yes & $<6$ weeks & Yes & Yes & Yes \\
\hline $\begin{array}{l}\text { VERTOS IV } \\
\text { Firanescu et }\left.a\right|^{27}\end{array}$ & 2018 & 1280 & 336 & $180(54 \%)$ & $\begin{array}{l}\text { Vertebroplasty vs } \\
\text { sham procedure }\end{array}$ & Yes & $<9$ weeks & No & Yes & Yes \\
\hline
\end{tabular}

*VOPE study has been presented as an abstract and is unpublished in peer review at this stage.

NR, not reported; NSM, non-surgical management.

pool of studies with regard to pain and functional outcomes. Of the 15 trials, four were designed as prospective, randomized, double-blind controlled trials and they will be reviewed in more detail below. The remaining studies are summarized in table 1 .

\section{PROSPECTIVE, RANDOMIZED, BLINDED OUTCOME CONTROLLED TRIALS}

Investigational Vertebroplasty Safety and Efficacy Trial (INVEST) (2009)

The INVEST trial was published in $2009 .{ }^{16}$ This prospective, multicenter, double-blind RCT compared VP to a sham procedure where VP was simulated. Inclusion criteria were age $\geq 50$ years, moderate to severe pain (Numeric Rating Scale (NRS) $\geq 3 / 10$ ), fracture age $<12$ months, age, and symptomatic nature of fracture confirmed with physical examination and imaging (MRI or plain radiographs). Of 1813 patients screened, 431 were found eligible and of these, 131 were enrolled (30\%); 68 patients $(52 \%)$ were randomized to VP and $63(48 \%)$ to the simulated/sham procedure. Average baseline fracture age in the VP and sham arms was 16 and 20 weeks, respectively. Patients randomized to the sham procedure underwent periosteal infiltration of bupivacaine, manual palpation to reproduce bone access, and mixing of polymethylmethacrylate (PMMA).

Primary outcome measures of average pain intensity at 1 month and change in the modified Rolland Morris Disability (RMD) questionnaire at 1 month were not reached (NRS, $p=0.19 ; R M D, p=0.49$ ). The secondary outcome measure of clinically meaningful improvement of pain at 1 month $(>30 \%$ reduction from baseline) was also not reached (64\% VP vs $48 \%$ sham procedure, $p=0.06)$. Of interest, had INVEST enrolled to its original target (subsequently revised lower due to slow enrollment) with the same percentage of positive responders, this secondary outcome of clinically meaningful improvement in pain would have favored VA with $\mathrm{p}<0.05$.

At 3 months, $51 \%$ of patients in the sham arm had crossed over to VP. Concerns have been raised regarding the applicability of INVEST to clinical practice due to this high crossover rate and the fact that $60 \%$ of fractures were aged $>3$ months. Further concerns included the underpowered nature of the study enrolling 131 out of the intended 250 patients, the absence of mandated MR or nuclear medicine bone scan evaluation for fracture acuity/symptomatology, slow enrollment (three patients/ 
center/year), a low baseline pain score of $3 / 10$, and the potential of the sham procedure representing an active treatment. Also, of note, patients with workers' compensation claims were included in the investigational cohorts. ${ }^{29}$

\section{Randomized trial of vertebroplasty for painful osteoporotic fractures} (2009)

A second prospective, multicenter, double-blind RCT comparing VP to sham procedure by Buchbinder et al was published in the same edition of the NEJM as INVEST in $2009 .{ }^{17}$ Of 468 patients screened, 219 were found eligible and, of these, 78 were enrolled (36\%). Thirty-eight patients (49\%) were randomized to VP and $40(51 \%)$ to the simulated/sham procedure. Inclusion criteria were back pain, MRI-confirmed vertebral fracture (denoted by fracture line and/or marrow edema), and fracture age of up to 12 months. The sham procedure involved periosteal docking of a 13-gauge bone needle at the pedicle, gentle tapping of the bone needle with a hammer, manipulation of the image intensifier, and mixing of PMMA to aid in simulation of the procedure. Average fracture age was 9 and 9.5 weeks in the VP and sham arms, respectively. Neither the primary outcome measure (NRS score for overall pain over the course of the previous week at 3 months) nor the secondary outcome measures (pain, disability and quality of life) were significant at designated time points.

As with INVEST, Buchbinder's trial enrolled patients with acute, subacute, and chronic fractures with the majority of lesions being between 3 and 6 months of age. Clinical outcomes were evaluated with mailed questionnaires and physical examination was not mandated. Similar to the INVEST trial, concerns have been raised regarding the applicability of the Buchbinder trial due to low enrollment, with $67 \%$ of cases being performed at one site by one physician, the absence of traditional collection of patient reported outcomes, an assessment of overall pain rather than back pain related to the fracture, and the low volume of cement injected per vertebral level. When cement volumes were studied following the release of the 2009 trials, a separate analysis concluded that the data "strongly indicates that the treatment arm includes patients who were not treated in a reasonably effective manner". ${ }^{30}$

Criticisms have also been raised regarding the method employed to calculate the difference in pain between the VP and sham groups and the underpowered trial design. The primary variable reported in the Buchbinder trial was the difference in mean pain scores between the groups rather than the difference in clinically relevant response rate. With the trial designed as it was, for a 1-point difference to be demonstrated between groups, 120 patients would have been required in each arm rather than the 35 and 38 patients that were enrolled.

As a result of these two highly controversial NEJM trials, profound and lasting changes have been noted in the utilization of VA both in the USA and internationally. In the USA, utilization of VA reduced by 32\% between 2004 and 2014. ${ }^{31}$ In other countries such as Australia and the Netherlands, VA utilization was essentially halted.

Vertebroplasty for Acute Painful Osteoporotic Compression Fractures (VAPOUR) (2016)

The Vertebroplasty for Acute Painful Osteoporotic Compression Fractures (VAPOUR) trial was published in 2016 in the Lancet. $^{26}$ This prospective, double-blind RCT was designed to specifically address the role of VP in patients with acute vertebral compression fractures associated with severe pain, thus differing from both the INVEST and Buchbinder trials. ${ }^{32} 33$ The sham procedure was similar to that of INVEST, aside from substitution of periosteal local anesthesia infiltration with subcutaneous infiltration. The VAPOUR authors considered periosteal local anesthesia at the dorsal pedicle an active treatment with significant potential for both medial branch and sinuvertebral nerve blockade. ${ }^{34} 35$ Olfactory simulation was also absent in VAPOUR as the cement kit used did not emit a characteristic PMMA odor.

Of 302 patients screened, 154 were found eligible and, of these, 120 were enrolled (78\%). Sixty-one patients (51\%) were randomized to VP and $59(49 \%)$ to the simulated/sham procedure. All fractures were $<6$ weeks of age with average baseline of 2.8 and 2.4 weeks for VP and sham groups, respectively. All patients had severe pain at baseline as indicated by NRS $>7$ (mean 8.6). MRI or bone scan evidence of fracture acuity was required.

The primary outcome measure of the percentage of patients with NRS pain score $<4$ over the past 24 hours at 14 days post treatment was significantly in favor of VP (44\% VP vs $21 \%$ sham; $\mathrm{p}=0.011)$. This effect was durable at each time point to 6 months. Secondary outcome measures of mean reduction in NRS scores, mean reduction in RDQ, QUALEFFO, and EQ-5D scores significantly favored the VP arm $(p<0.05)$. Reduction in analgesic use also favored the VP arm $(p<0.05)$. The incidence of new fractures was similar between the two arms. Fifty-seven percent of patients enrolled were hospital inpatients. The potential for outcome bias in VAPOUR has been raised with $85 \%$ of patients enrolled by one of the four included sites.

\section{Hospital length of stay data from VAPOUR}

Median hospital length of stay was reduced by 5.5 days in the VP group in the VAPOUR trial. Of note, the attending physicians were masked as to the procedure, so that discharge decisions were based on clinical improvement rather than treatment allocation. Shorter inpatient hospital stays and lower readmission rates for patients treated with VA have been described previously. ${ }^{36} 37$

Vertebroplasty vs Sham Procedure for Painful Osteoporotic Vertebral Compression Fractures (VERTOS IV) (2018)

The Vertebroplasty vs Sham Procedure for Painful Osteoporotic Vertebral Compression Fractures (VERTOS IV) trial was published in the $B M J$ in 2018. This prospective, double-blind RCT intended to evaluate pain relief in acute fractures $<6$ weeks of age. However, at 6 months after initiating recruitment, a protocol amendment was initiated and fracture age inclusion criteria extended to 9 weeks secondary to slow enrollment. Further inclusion criteria included the presence of back pain with VAS of $\geq 5$ and marrow edema on MRI.

Of 1280 patients screened, 336 were found eligible and, of these, 180 were enrolled (54\%). A total of 176 patients were randomized, $90(51 \%)$ of which were allocated to VP and 86 $(49 \%)$ to the simulated/sham procedure. One-year follow-up data were available on 156/176 (89\%) patients. Both VP and sham arm patients received local anesthesia and sedation where appropriate. Bilateral stab incisions were performed at the vertebral level in both groups and bone needles were either advanced using a standard transpedicular approach or docked at the pedicle depending on randomization to VP or sham. In both groups, PMMA was prepared in close proximity to the patient and, in the sham arm, cement delivery was simulated using olfactory, physical, and verbal cues.

The primary outcome measure of mean reduction of VAS score was statistically significant in the VP and sham procedure groups 
Table 2 Summary characteristics and outcomes of the published prospective multicenter sham procedure RCTs on vertebroplasty for osteoporotic fractures

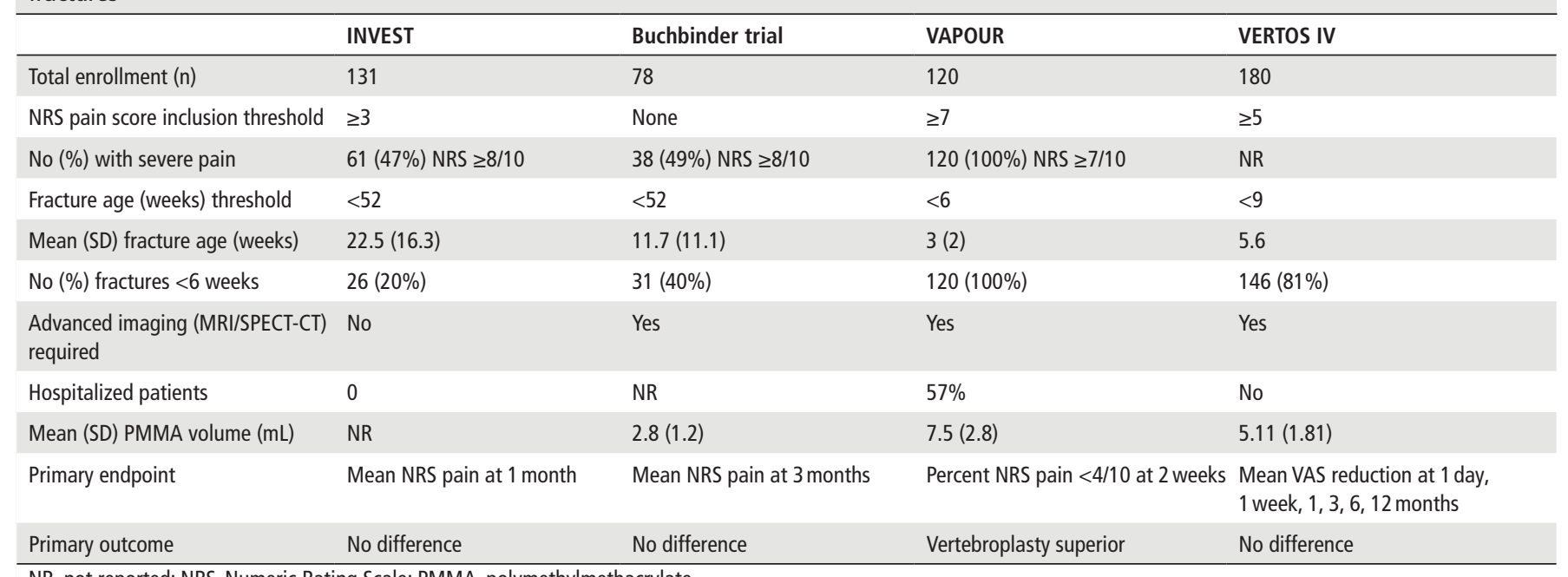

NR, not reported; NRS, Numeric Rating Scale; PMMA, polymethylmethacrylate.

at all follow-up points when compared with baseline. However, no significant difference was demonstrated between the two arms at any time point. Secondary outcome measures of reduction in RDQ or QUALEFFO scores were also non-significant between each group. Importantly, significant differences were identified in the number of patients with residual VAS $>5$ at 12 months in favor of VP ( $20 \%$ VP vs $41 \%$ sham, $\mathrm{p}=0.005)$.

Both the VERTOS IV and the VAPOUR trials demonstrated lasting vertebral body height preservation in the VP population and, conversely, significant ongoing vertebral body height loss and deformity in those subjects randomized to the sham treatment. Spinal deformity with the consequent altered spinal dynamics and global spinal imbalance have been described previously to contribute to the increased morbidity and mortality in the VCF population. ${ }^{38}$

Critics of VERTOS IV highlight concerns with patient selection, citing a selection bias for those with less severe pain syndromes in spite of its use of a minimum VAS scale score of 5. In VERTOS IV, despite all subjects reporting moderate to severe pain (VAS $>5 / 10$ ), approximately one-third required strong opiates.

In comparing the four prospective randomized blinded shamcontrolled trials, there is significant heterogeneity in inclusion criteria, treatment procedures, and outcomes measured. These are summarized in table 2. All trials focused on the outcome of pain, while all had variable inclusion criteria ranging from mild (NRS $\geq 3$ ) in INVEST to severe (NRS $\geq 7$ ) in VAPOUR. Time from fracture to inclusion ranged from a mean of 3 weeks in VAPOUR to a mean of 22 weeks in INVEST. Cement volume injected during the procedure ranged from $2.8 \mathrm{~mL}$ in the Buchbinder trial to $7.5 \mathrm{~mL}$ in VAPOUR. Notably, VAPOUR is the only RCT which is overwhelmingly positive. Important differences in these observed outcomes might relate to $100 \%$ of included patients being within 6 weeks of fracture onset, the hospitalized cohort comprising the majority of the participants, the high baseline pain rating, and the volume of cement used per level.

\section{COMPLICATION RISK AS ESTIMATED FROM THE 14 RCTS}

Complications associated with VP/BKP were reported in 10 of the described 15 RCTs. Of the 1098 patients treated with VP, 16 procedure-related complications were reported $(1.5 \%)$. Of these, two $(0.18 \%)$ were considered serious adverse events. One patient assigned to the VP group of the Buchbinder study was unable to receive prophylactic antibiotics owing to multiple drug allergies. Following VP, an adjacent level new fracture and subsequent osteomyelitis developed. ${ }^{17}$ In VAPOUR, a patient suffered respiratory arrest following initiation of sedation and was resuscitated successfully, undergoing the procedure 2 days later. No procedure-related deaths were reported in the 15 included trials. Of note, there were two serious adverse events in the sham treatment arm of VAPOUR with both patients developing spinal cord compression due to interval collapse and retropulsion of the fracture a few weeks after enrollment. One patient underwent spinal decompression with resolution of the neurological deficit. The other patient was not considered a surgical candidate and became paraplegic. Given the extensive safety analysis of VP/ $\mathrm{BKP}$, it is reasonable to conclude that it is very safe.

\section{SUBSEQUENT FRACTURE RISK AND FURTHER HEIGHT LOSS FOLLOWING KYPHOPLASTY AND VERTEBROPLASTY}

Adjacent or remote level vertebral fractures are commonly encountered in patient follow-up after VA. ${ }^{39}$ Until recently, opinion has been divided as to whether VA increased a patient's risk of subsequent adjacent level fractures or whether this phenomenon is primarily a function of underlying metabolic bone disease and altered mechanical stressors due to spinal deformity. Some authors have suggested that VA is protective and may reduce the rate of adjacent fractures through sagittal balance restoration/maintenance and by conserving physiologic mechanical loading of the vertebral endplates. ${ }^{4041}$

A prospective study by Yi et al with 290 consecutive patients showed no statistically significant difference in the rate of VCFs between the VA and NSM groups, but additional VCFs occurred sooner in the VA group than in the NSM group. ${ }^{42}$ This may explain the tendency to assume that more fractures happen in the VA group than in the NSM group because they happen in closer time proximity to the incident fracture. A recent metaanalysis from 2017 comprising 1328 patients also found no increased risk for adjacent or remote level vertebral body fracture following augmentation using VP or BKP when compared with NSM. ${ }^{43}$ A review of the 15 RCTs discussed in this paper show two studies in which a statistically significant difference was seen in the rate of adjacent vertebral fractures in follow-up between the VA and control groups, one favoring VA and the 
Table 3 Rate of subsequent vertebral compression fractures (VCFs) reported from the randomized controlled studies performed to date investigating the role of vertebroplasty and kyphoplasty in the treatment of acute, subacute, and chronic VCF

\begin{tabular}{|c|c|c|c|c|c|c|}
\hline $\begin{array}{l}\text { Study name/lead } \\
\text { author }\end{array}$ & Year published & $\begin{array}{l}\text { No of patients } \\
\text { enrolled (\% of } \\
\text { total eligible for } \\
\text { enrollment) }\end{array}$ & $\begin{array}{l}\text { Subsequent fracture } \\
\text { rate in treatment } \\
\text { arm }(\%)\end{array}$ & $\begin{array}{l}\text { Subsequent fracture } \\
\text { rate in control arm } \\
(\%)\end{array}$ & $\begin{array}{l}\text { Statistical significance } \\
\text { reached }\end{array}$ & $\begin{array}{l}\text { Follow-up period } \\
\text { (weeks) }\end{array}$ \\
\hline $\begin{array}{l}\text { VERTOS } \\
\text { Voormolen et al }{ }^{14}\end{array}$ & 2007 & 34 & 11 & 0 & No & 2 \\
\hline $\begin{array}{l}\text { FREE } \\
\text { Wardlaw et } a l^{15}\end{array}$ & 2009 & $300(49 \%)$ & $\begin{array}{l}33^{*} \\
47.5^{*}\end{array}$ & $\begin{array}{l}25^{*} \\
44.1^{*}\end{array}$ & $\begin{array}{l}\text { No } \\
\text { No }\end{array}$ & $\begin{array}{l}52 \\
104\end{array}$ \\
\hline $\begin{array}{l}\text { INVEST } \\
\text { Kallmes et al }\end{array}$ & 2009 & $131(30 \%)$ & NR & NR & NR & NR \\
\hline Buchbinder et al ${ }^{17}$ & 2009 & $78(36 \%)$ & 7.9 & 10 & No & 26 \\
\hline Rousing et $a l^{18}$ & 2010 & 49 & 12 & 16.7 & No & 52 \\
\hline $\begin{array}{l}\text { VERTOS II } \\
\text { Klazen et al }{ }^{19}\end{array}$ & 2010 & $202(47 \%)$ & 16.5 & 24.7 & No & 52 \\
\hline Farrokhi et $a^{20}$ & 2011 & $82(100 \%)$ & 2.6 & 15.4 & Yes & 104 \\
\hline Blasco et a $\left.\right|^{21}$ & 2012 & $125(100 \%)$ & 27 & 13 & Yes & 52 \\
\hline Chen et $a l^{22}$ & 2014 & 96 & NR & NR & NR & NR \\
\hline Leali et $a l^{23}$ & 2016 & 385 & 1.8 & 0 & No & 26 \\
\hline Yang et $a l^{24}$ & 2016 & $135(85 \%)$ & 8.9 & 7.8 & No & 52 \\
\hline Wang et $a l^{25}$ & 2016 & $217(69 \%)$ & 13 & 10 & No & 52 \\
\hline $\begin{array}{l}\text { VOPE } \\
\text { Hansen et } a^{28}\end{array}$ & 2016 & 46 & NR & NR & NR & NR \\
\hline $\begin{array}{l}\text { VAPOUR } \\
\text { Clark et } a l^{26}\end{array}$ & 2016 & $120(78 \%)$ & 6 & 4 & No & 26 \\
\hline $\begin{array}{l}\text { VERTOS IV } \\
\text { Firanescu et al }{ }^{27}\end{array}$ & 2018 & $180(54 \%)$ & $39 \%$ & $37 \%$ & No & 52 \\
\hline
\end{tabular}

${ }^{*}$ New or worsening radiographic vertebral fractures in follow-up.

NR, not reported.

other NSM (table 3). In addition, VP and BKP may be protective against further height loss of a fractured vertebra. In VERTOS 4, the risk of further height loss was almost 10 times higher after the sham procedure compared with VA treatment. As with procedural safety, it is also reasonable to conclude that VA does not affect subsequent fracture risk.

\section{POPULATION AND CLAIMS-BASED DATA WITH RESPECT TO SHORT- AND LONG-TERM MORBIDITY AND MORTALITY RISK FOLLOWING VCF}

Clinically apparent and asymptomatic VCFs or deformities are associated with an increased risk of death. ${ }^{44} 45$ The excess mortality risk from VCF has been estimated to range between $2 \%$ and $42 \%$ at 12 months. ${ }^{46}$ Numerous national registry and insurance datasets from various countries have been analyzed in an attempt to clarify the short- and long-term morbidity and mortality risk in patients with VCFs who have undergone either NSM or VA. ${ }^{47-52}$ One analysis of 858978 patients with new VCF from the US Medicare dataset collected between 2005 and 2008 found a significant adjusted survival benefit at up to 4 years follow-up for patients who underwent VA compared with those who received NSM $\left(60.8 \%\right.$ vs $50.0 \%$; p<0.001). ${ }^{47}$ The same study found a survival advantage for BKP over VP that remained significant $(62.8 \%$ vs $57.3 \%$; $<0.001)$. In a separate analysis published in 2013, the 2006 Medicare provider analysis and review database was used to identify 68752 patients with VCFs. ${ }^{48}$ These patients were then separated into those who underwent NSM (55.6\%), VP (11.2\%), and BKP (33.2\%). Estimated 3-year survival rates were $42.3 \%, 49.7 \%$, and $59.9 \%$ for NSM, VP, and BKP groups, respectively. Adjusted risk of mortality was $20 \%$ lower in the group that received BKP compared with the VP group ( $\mathrm{HR}=0.8,95 \% \mathrm{CI} 0.77$ to 0.84$)$. The authors noted that patients who received VA had a shorter hospital stay and less pneumonia and fewer decubitus ulcers in the 6-month postoperative period.

In Germany, claims data from a major health insurance fund between 2006 and 2010 were analyzed and mortality risk differences between patients with VCF who underwent VA compared with those who were managed with NSM were determined. ${ }^{49}$ Of 3607 patients identified with VCFs, 598 underwent intervention with VA. The authors found individuals from the VA cohort were $43 \%$ less likely to die than the NSM cohort in the 5 -year study period $(\mathrm{HR}=0.57 ; \mathrm{p}<0.001)$. Patients who underwent BKP showed a non-significant higher 60-month adjusted survival rate $(66.7 \%)$ compared with those who received VP $(58.7 \%)(\mathrm{p}=0.68)$.

Subsequent population-based studies employed propensity score matching to avoid treatment selection bias by accounting for the covariates that may predict a patient receiving specific treatment over another. Edidin et al identified 1038956 patients with new VCFs from the US Medicare dataset between 2005 and 2009 and compared mortality outcomes for those patients who underwent VA (BKP 141 343; VP 75 364) and NSM. ${ }^{50}$ Patients who underwent NSM for VCFs had a $25 \%$ higher adjusted mortality risk than those who underwent VP $(p<0.001)$ and a 55\% higher adjusted mortality risk than those who had BKP $(\mathrm{p}<0.001)$. When propensity matched, the NSM group had a significantly higher adjusted risk of pneumonia, 
acute myocardial infarction, deep venous thrombosis, and urinary tract infections.

A recent analysis of the inpatient/outpatient Medicare claims dataset between 2005 and 2014 sought to determine if a known downturn in the use of VA in 2009 following the publication of INVEST and Buchbinder's RCTs was associated with a shift in mortality risk for patients with new VCFs. ${ }^{51}$ They identified 2129769 patients over the period with newly diagnosed VCFs. Rates of VA in VCF patients rose from 20\% to 24\% between 2005 and 2009. This rate of intervention fell to $14 \%$ in the 5 years following to 2014 . The propensity-adjusted mortality risk for patients with VCF was 4\% greater in the 2010-2014 period compared with the 2005-2009 period. The authors identified a $19 \%$ lower propensity-adjusted 10-year mortality risk for BKP versus NSM $(\mathrm{p}<0.001)$ and a $7 \%$ lower propensity-adjusted 10 -year mortality risk for VP versus NSM $(p<0.001)$.

Critics of these studies have cited underlying patient frailty as a confounding variable that may add bias and artificially strengthen an association between fracture and mortality resulting in false positive associations. The FORMEN cohort study from 2017 sought to evaluate the association between fractures and mortality in an elderly population while adjusting for the pre-fracture frailty levels of the included subjects. The authors found that incident fractures, especially osteoporotic VCFs, were associated with an increased risk of death even after adjusting for pre-fracture frailty status. ${ }^{53}$

\section{CONSIDERATIONS REGARDING SUBSEQUENT TRIAL DESIGN}

Ethical consideration should be given to any trial type including a sham or non-treatment arm, given the significantly increased risk of morbidity and mortality in patients who do not undergo VA for painful VCFs. A short-term crossover design with an intention to treat analysis or a relatively limited follow-up time period may suffice to alleviate these concerns. Inconsistencies in trial design between the available RCTs to date should be settled, and a unified approach for appropriate patient selection, effective interventional technique, and rigorous and reliable statistical method should be employed. Patient-specific (ie, pain and disability/function scales), anatomical (kyphosis correction), and health economic outcome measures should be sought.

\section{REVIEW LIMITATIONS}

This review has limitations. RCTs that enrolled $<50$ patients, those that were not blinded, and those that compared VA to NSM were not elaborated on outside the provided tables, nor did we review the data for third-generation VA systems such as the Kiva VCF treatment system, vertebral body stenting (VBS), or SpineJack. It should be noted that prominent studies that fulfil these criteria - namely, the FREE trial, VERTOS II, the KAST trial, and the recently published SAKOS trial-all showed significant benefit for BKP and instrumented VA in the management of VCFs. 9151941

\section{CONCLUSION}

Debate has surrounded the role of VA in the treatment of osteoporotic VCFs since the publication of two randomized studies in 2009 showing no superiority of the intervention over a sham procedure. Widespread concern has been raised regarding the design and execution of these studies and hence their applicability to daily practice. Regardless, these studies have shaped referring patterns in the USA and markedly influenced public healthcare policy and funding in other countries, severely limiting the availability of this valuable treatment to large at-risk patient populations. While the RCT data are conflicting, there are patients with acute fractures causing significant pain and disability who can derive benefit with respect to improvement in pain outcomes, reduction in narcotic usage, and reduced length of hospital stay. A further consistency throughout the literature is the excellent safety profile of VA and a confirmation that VA does not increase the risk of adjacent or remote VCF. What might also be considered are numerous positive RCTs comparing VA to NSM as the control arm, which arguably more closely reflect clinical practice, in addition to the well-described survival and morbidity benefit for patients who receive VA compared with NSM.

\section{Author affiliations}

${ }^{1}$ Departments of Neurosurgery \& Radiology, Icahn School of Medicine at Mount Sinai, New York City, New York, USA

${ }^{2}$ Interventional Neuroradiology, Monash Health, Clayton, Victoria, Australia ${ }^{3}$ Monash University Faculty of Medicine Nursing and Health Sciences, Clayton, Victoria, Australia

${ }^{4}$ Department of Radiology, University of Texas Southwestern Medical Center at Dallas, Dallas, Texas, USA

${ }^{5}$ Department of Radiology, Montefiore Medical Center, Bronx, New York, USA ${ }^{6}$ Department of Neuroradiology, Neurocenter of Southern Switzerland, Ospedale Regionale di Lugano, Lugano, Switzerland

${ }^{7}$ San Diego Imaging, Oceanside, California, USA

${ }^{8}$ Department of Radiology, St Vincent's Hospital, Melbourne, Victoria, Australia

${ }^{9}$ Department of Radiology, Elisabeth-TweeSteden Ziekenhuis, Tilburg, Noord-Brabant, The Netherlands

${ }^{10}$ Department of Radiology, IOM Mediterranean Oncology Institute, Viagrande, Sicily, Italy

${ }^{11}$ Department of Radiology, SS Trinita Hospital, Cagliari, Sardinia, Italy

${ }^{12}$ Department of Neurosurgery, Mount Sinai Health System, New York City, New York, USA

${ }^{13}$ Neurolnterventional Radiology, MGH, Boston, Massachusetts, USA

Correction notice Since this article was first published online, the author name Josh has been updated to Joshua.

Twitter Reade De Leacy @rdeleacymd and Ashu Jhamb @Dr Ashu Jhamb

Contributors RDL, RVC, and JAH researched, prepared, and wrote the manuscript. $J D B, A B, A C, B G, A J, P L, L M, S M, A V$, and $D B$ aided in data analysis, proof reading, and redrafting the manuscript.

Funding The authors have not declared a specific grant for this research from any funding agency in the public, commercial or not-for-profit sectors.

Competing interests RDL is a consultant for Cerenovus, Imperative Care and Siemens. AB is a consultant for Medtronic and Stryker. BG is a speaker for Merit Medical. SM is a consultant for Stryker and Techlamed. JAH is a consultant for Medtronic and grant recipient from the Nieman Health Policy Institute.

Patient consent for publication Not required.

Provenance and peer review Commissioned; externally peer reviewed.

\section{ORCID iD}

Reade De Leacy http://orcid.org/0000-0001-9447-5338

\section{REFERENCES}

1 Office of the Surgeon General (US). Bone health and osteoporosis: a report of the surgeon General, 2004.

2 Burge R, Dawson-Hughes B, Solomon DH, et al. Incidence and economic burden of osteoporosis-related fractures in the United States, 2005-2025. J Bone Miner Res 2007;22:465-75.

3 Gold DT. The nonskeletal consequences of osteoporotic fractures. Psychologic and social outcomes. Rheum Dis Clin North Am 2001;27:255-62.

4 Babayev M, Lachmann E, Nagler W. The controversy surrounding sacral insufficiency fractures: to ambulate or not to ambulate? Am J Phys Med Rehabil 2000:79:404-9.

5 Galibert P, Deramond H, Rosat P, et al. [Preliminary note on the treatment of vertebral angioma by percutaneous acrylic vertebroplasty]. Neurochirurgie 1987;33:166-8.

6 Lapras C, Mottolese C, Deruty R, et al. [Percutaneous injection of methyl-metacrylate in osteoporosis and severe vertebral osteolysis (Galibert's technic)]. Ann Chir 1989;43:371-6.

7 Garfin SR, Yuan HA, Reiley MA. New technologies in spine: kyphoplasty and vertebroplasty for the treatment of painful osteoporotic compression fractures. Spine 2001;26:1511-5. 
8 Noriega D, Maestretti G, Renaud C, et al. Clinical performance and safety of 108 SpineJack implantations: 1-year results of a prospective multicentre single-arm registry study. Biomed Res Int 2015;2015:1-10.

9 Tutton SM, Pflugmacher R, Davidian M, et al. KAST study: the Kiva system as a vertebral augmentation treatment-A safety and effectiveness trial: a randomized, noninferiority trial comparing the Kiva system with balloon kyphoplasty in treatment of osteoporotic vertebral compression fractures. Spine 2015;40:865-75.

10 Wallace AN, Robinson CG, Meyer J, et al. The metastatic spine disease multidisciplinary Working Group algorithms. Oncologist 2015;20:1205-15.

11 Chandra RV, Meyers PM, Hirsch JA, et al. Vertebral augmentation: report of the standards and guidelines Committee of the Society of Neurolnterventional Surgery. J Neurointerv Surg 2014;6:7-15.

12 pp. Tsoumakidou G, Too CW, Koch G, et al. CIRSE guidelines on percutaneous vertebral augmentation. Cardiovasc Intervent Radiol 2017;40:331-42.

13 Barr JD, Jensen ME, Hirsch JA, et al. Position statement on percutaneous vertebral augmentation: a consensus statement developed by the Society of Interventional Radiology (SIR), American Association of Neurological Surgeons (AANS) and the Congress of Neurological Surgeons (CNS), American College of Radiology (ACR), American Society of Neuroradiology (ASNR), American Society of Spine Radiology (ASSR), Canadian Interventional Radiology Association (CIRA), and the Society of Neurolnterventional Surgery (SNIS). J Vasc Interv Radiol 2014;25:171-81.

14 Voormolen MHJ, Mali WPTM, Lohle PNM, et al. Percutaneous vertebroplasty compared with optimal pain medication treatment: short-term clinical outcome of patients with subacute or chronic painful osteoporotic vertebral compression fractures. The VERTOS study. AJNR Am J Neuroradio/ 2007;28:555-60.

15 Wardlaw D, Cummings SR, Van Meirhaeghe J, et al. Efficacy and safety of balloon kyphoplasty compared with non-surgical care for vertebral compression fracture (FREE): a randomised controlled trial. The Lancet 2009;373:1016-24.

16 Kallmes DF, Comstock BA, Heagerty PJ, et al. A randomized trial of vertebroplasty for osteoporotic spinal fractures. N Engl J Med 2009;361:569-79.

17 Buchbinder R, Osborne RH, Ebeling PR, et al. A randomized trial of vertebroplasty for painful osteoporotic vertebral fractures. N Engl J Med 2009;361:557-68.

18 Rousing R, Hansen KL, Andersen MO, et al. Twelve-months follow-up in forty-nine patients with acute/semiacute osteoporotic vertebral fractures treated conservatively or with percutaneous vertebroplasty. Spine 2010;35:478-82.

19 Klazen CAH, Lohle PNM, de Vries J, et al. Vertebroplasty versus conservative treatment in acute osteoporotic vertebral compression fractures (Vertos II): an open-label randomised trial. The Lancet 2010;376:1085-92.

20 Farrokhi MR, Alibai E, Maghami Z. Randomized controlled trial of percutaneous vertebroplasty versus optimal medical management for the relief of pain and disability in acute osteoporotic vertebral compression fractures. J Neurosurg 2011;14:561-9

21 Blasco J, Martinez-Ferrer A, Macho J, et al. Effect of vertebroplasty on pain relief, quality of life, and the incidence of new vertebral fractures: a 12-month randomized follow-up, controlled trial. J Bone Miner Res 2012;27:1159-66.

22 Chen D, An Z-Q, Song S, et al. Percutaneous vertebroplasty compared with conservative treatment in patients with chronic painful osteoporotic spinal fractures. $J$ Clin Neurosci 2014:21:473-7.

23 Leali PT, Solla F, Maestretti G, et al. Safety and efficacy of vertebroplasty in the treatment of osteoporotic vertebral compression fractures: a prospective multicenter international randomized controlled study. Clin Cases Miner Bone Metab 2016:13:234-6.

24 Yang E-Z, Xu J-G, Huang G-Z, et al. Percutaneous vertebroplasty versus conservative treatment in aged patients with acute osteoporotic vertebral compression fractures: a prospective randomized controlled clinical study. Spine 2016;41:653-60.

25 Wang B, Guo H, Yuan L, et al. A prospective randomized controlled study comparing the pain relief in patients with osteoporotic vertebral compression fractures with the use of vertebroplasty or facet blocking. Eur Spine J 2016;25:3486-94.

26 Clark W, Bird P, Gonski P, et al. Safety and efficacy of vertebroplasty for acute painful osteoporotic fractures (VAPOUR): a multicentre, randomised, double-blind, placebocontrolled trial. The Lancet 2016:388:1408-16.

27 Firanescu CE, de Vries J, Lodder P, et al. Vertebroplasty versus sham procedure for painful acute osteoporotic vertebral compression fractures (VERTOS IV): randomised sham controlled clinical trial. BMJ 2018;362.

28 Hansen EJ, Simony A, Rousing R, et al. Double blind placebo-controlled trial of percutaneous vertebroplasty (VOPE). Global Spine J 2016;6.
29 Saxena AP, Hirsch AE, Yoo AJ, et al. The use of advanced imaging and representation of workers compensation in vertebral augmentation: a single-center comparison with the invest trial. Pain Physician 2013;16:E391-6.

30 Boszczyk B. Volume matters: a review of procedural details of two randomised controlled vertebroplasty trials of 2009. Eur Spine J 2010;19:1837-40.10.1007/ s00586-010-1525-4

31 Hirsch JA, Chandra RV, Pampati V, et al. Analysis of vertebral augmentation practice patterns: a 2016 update. J Neurointerv Surg 2016;8:1299-304.

32 De Leacy R. New, high-quality evidence for vertebroplasty in the management of painful recent compression fractures: review of the VAPOUR trial. World Neurosurg 2016:96:596-8.

33 Hirsch JA, Chandra RV. Resurrection of evidence for vertebroplasty? The Lancet 2016:388:1356-7.

34 Bogduk N, MacVicar J, Borowczyk J. The pain of vertebral compression fractures can arise in the posterior elements. Pain Med 2010;11:1666-73.

35 Manchikanti L, Giordano J, Fellows B, et al. Placebo and nocebo in interventional pain management: a friend or a foe--or simply foes? Pain Physician 2011;14:E157-75.

36 Tsai Y-W, Hsiao F-Y, Wen Y-W, et al. Clinical outcomes of vertebroplasty or kyphoplasty for patients with vertebral compression fractures: a nationwide cohort study. J Am Med Dir Assoc 2013;14:41-7.

37 Maravic M, Taupin P, Roux C. Hospital burden of vertebral fractures in France: influence of vertebroplasty. Osteoporos Int 2013;24:2001-6.

38 Yuan HA, Brown CW, Phillips FM. Osteoporotic spinal deformity: a biomechanical rationale for the clinical consequences and treatment of vertebral body compression fractures. J Spinal Disord Tech 2004;17:236-42

39 Uppin AA, Hirsch JA, Centenera LV, et al. Occurrence of new vertebral body fracture after percutaneous vertebroplasty in patients with osteoporosis. Radiology 2003:226:119-24.

40 Movrin I, Wochenschrift I. Adjacent level fracture after osteoporotic vertebral compression fracture: a nonrandomized prospective study comparing balloon kyphoplasty with conservative therapy. Wien Klin Wochenschr 2012;124:304-11.

41 Noriega D, Marcia S, Theumann N, et al. A prospective, international, randomized, noninferiority study comparing an implantable titanium vertebral augmentation device versus balloon kyphoplasty in the reduction of vertebral compression fractures (SAKOS study). Spine J 2019;19:1782-95.

42 Yi X, Lu H, Tian F, et al. Recompression in new levels after percutaneous vertebroplasty and kyphoplasty compared with conservative treatment. Arch Orthop Trauma Surg 2014; 134:21-30

43 Zhang H, Xu C, Zhang T, et al. Does percutaneous vertebroplasty or balloon Kyphoplasty for osteoporotic vertebral compression fractures increase the incidence of new vertebral fractures? A meta-analysis. Pain Physician 2017;20:E13-28.

44 Cauley JA, Thompson DE, Ensrud KC, et al. Risk of mortality following clinical fractures. Osteoporosis Int 2000;11:556-61.

45 Kado DM, Browner WS, Palermo L, et al. Vertebral fractures and mortality in older women: a prospective study. Study of Osteoporotic Fractures Research Group. Arch Intern Med 1999;159:1215-20.

46 Sattui SE, Saag KG. Fracture mortality: associations with epidemiology and osteoporosis treatment. Nat Rev Endocrinol 2014;10:592-602.

47 Edidin AA, Ong KL, Lau E, et al. Mortality risk for operated and nonoperated vertebral fracture patients in the Medicare population. J Bone Miner Res 2011;26:1617-26.

48 Chen AT, Cohen DB, Skolasky RL. Impact of nonoperative treatment, vertebroplasty, and kyphoplasty on survival and morbidity after vertebral compression fracture in the Medicare population. J Bone Joint Surg Am 2013;95:1729-36.

49 Lange A, Kasperk C, Alvares L, et al. Survival and cost comparison of kyphoplasty and percutaneous vertebroplasty using German claims data. Spine 2014;39:318-26.

50 Edidin AA, Ong KL, Lau E, et al. Morbidity and mortality after vertebral fractures. Spine 2015;40:1228-41.

51 Ong KL, Beall DP, Frohbergh M, et al. Were VCF patients at higher risk of mortality following the 2009 publication of the vertebroplasty "sham" trials? Osteoporosis Int 2018;29:375-83.

52 McCullough BJ, Comstock BA, Deyo RA, et al. Major medical outcomes with spinal augmentation vs conservative therapy. JAMA Intern Med 2013;173:1514-21.

53 Iki M, Fujita Y, Tamaki J, et al. Incident fracture associated with increased risk of mortality even after adjusting for frailty status in elderly Japanese men: the Fujiwara-kyo osteoporosis risk in men (FORMEN) cohort study. Osteoporos Int 2017;28:871-80 